Case Reports in
Gastroenterology
Case Rep Gastroenterol 2020;14:402-408

DOI: $10.1159 / 000508859$

Published online: July 30, 2020

(C) 2020 The Author(s)

Published by S. Karger AG, Basel

www.karger.com/crg

This article is licensed under the Creative Commons Attribution-NonCommercial 4.0 International License (CC BY-NC) (http://www.karger.com/Services/OpenAccessLicense). Usage and distribution for commercial purposes requires written permission.

\title{
Recurrence of Noninvasive Perianal Extramammary Paget's Disease in the Lymph Nodes without Local Recurrence after Complete Excision
}

\author{
Yoshiaki Maeda Nozomi Minagawa Ryota Koyama \\ Tadayuki Kobayashi Akira Saito Toshiki Shinohara \\ Department of Gastrointestinal Surgery, Hokkaido Cancer Center, Shiroishi, Japan
}

\section{Keywords}

Noninvasive perianal extramammary Paget's disease - Lymph node metastasis · Local recurrence

\begin{abstract}
Primary extramammary Paget's disease (EMPD) is a rare intraepithelial adenocarcinoma. Lymph node metastasis from noninvasive EMPD originating in the anorectal region is extremely rare, and the recurrence of noninvasive EMPD is commonly associated with local recurrence mainly due to an insufficient resection margin. We herein report a case of inguinal and para-aortic lymph node recurrence without local recurrence after complete margin-free surgical resection of noninvasive perianal EMPD. The patient was a man in his 40 s who presented with an erythematous plaque of $7 \times 5 \mathrm{~cm}$ in the perianal region, which had been present for 1 year. Biopsy from the perianal skin suggested EMPD; it was positive for cytokeratin (CK)7 and negative for CK20. Underlying malignancy was ruled out based on whole-body enhanced computed tomography (CT) and total colonoscopy. Surgery including complete wide resection of the lesion with preservation of the rectum was performed, and VY-advancement flap
\end{abstract}




\section{Case Reports in Gastroenterology}

\begin{tabular}{l|l}
\hline Case Rep Gastroenterol 2020;14:402-408 \\
\hline DOI: 10.1159/000508859 & $\begin{array}{l}\text { ○ 2020 The Author(s). Published by S. Karger AG, Basel } \\
\text { www.karger.com/crg }\end{array}$ \\
\hline
\end{tabular}

Maeda et al.: Recurrence of Noninvasive Perianal Extramammary Paget's Disease in the Lymph Nodes without Local Recurrence after Complete Excision

reconstruction and flap-rectum anastomosis were performed. A histological examination of the whole specimen with $5-\mathrm{mm}$ slices confirmed noninvasive EMPD resected with all-negative surgical margins. At 2 years and 6 months after surgery, however, enlargement of the inguinal and para-aortic lymph nodes was detected by follow-up enhanced $C T$, and the recurrence of EMPD was diagnosed based on left inguinal lymph node biopsy. The patient underwent chemotherapy without a remarkable response. He died of the disease 53 months after the first surgery. This is the first case report of lymph node metastasis without local recurrence after complete margin-free resection of noninvasive perianal EMPD.

(C) 2020 The Author(s)

Published by S. Karger AG, Basel

\section{Introduction}

Extramammary Paget's disease (EMPD) is a rare intraepithelial adenocarcinoma commonly originating in the anorectal region. Reported cases of EMPD are limited, so the treatment remains controversial and more experience should be shared. Invasive EMPD occasionally metastasizes to the inguinal lymph nodes $[1,2]$ and subsequently spreads to nonregional lymph nodes. However, reports of lymph node or distant metastasis from noninvasive EMPD are extremely rare [3-5]. In noninvasive cases, lymph node metastasis commonly occurs after local recurrence. We herein report an extremely rare case of noninvasive perianal EMPD that recurred in the inguinal and para-aortic lymph nodes without local recurrence after marginfree complete resection.

\section{Case Report}

A man in his 40s was referred to our hospital with a 1-year history of pruritus, erythematous and eczematoid skin rash with pain in the perianal regions. He had been suffering from the symptoms without a proper diagnosis for 1 year. The patient's medical history was unremarkable. A physical examination revealed an erythematous plaque of $7 \times 5 \mathrm{~cm}$ in size in the perianal region, with erosive and eczematous change. A pathological examination of a biopsy of the perianal skin suggested EMPD. To exclude an underlying malignancy, the patient received whole-body enhanced computed tomography (CT), which showed no sign of rectal of urological malignancy. Total colonoscopy showed no sign of colorectal primary cancer, and the perianal skin lesion had not invaded the rectal mucosa or exceeded the dentate line. A physical examination, ultrasound examination, and enhanced CT revealed no signs of regional lymph node or distant metastasis. The results of all laboratory examinations were normal, including carcinoembryonic antigen and squamous cell carcinoma-related antigen levels. Preoperative mapping biopsy was performed at 8 points around the lesion and all were negative.

Surgery including complete wide excision of the lesion with preservation of the rectum was planned. The patient was placed in a jack-knife position after anesthesia. Circumferential wide excision was performed with a margin of at least $2.5 \mathrm{~cm}$ (Fig. 1a). Subcutaneous fat tissue was resected to a thickness of approximately $10 \mathrm{~mm}$ in order to assure a complete vertical margin. Resection was performed into the inter-sphincter space between the internal and external sphincter muscle of the lower rectum. The lower rectum was resected continuously 


\section{Case Reports in Gastroenterology}

\begin{tabular}{l|l}
\hline Case Rep Gastroenterol 2020;14:402-408 \\
\hline DOI: 10.1159/000508859 & $\begin{array}{l}\text { @ 2020 The Author(s). Published by S. Karger AG, Basel } \\
\text { www.karger.com/crg }\end{array}$ \\
\hline
\end{tabular}

Maeda et al.: Recurrence of Noninvasive Perianal Extramammary Paget's Disease in the Lymph Nodes without Local Recurrence after Complete Excision

with the perianal skin over a length of $3 \mathrm{~cm}$ from the dentate line, and the external sphincter muscle was preserved (Fig. 1b). Intraoperative frozen sections from both skin edges and the rectum mucosa were examined, and all margins were confirmed to be negative. The residual defect was closed using a VY-advancement flap, and anastomosis of the flap and residual rectum was performed (Fig. 1c, d). Subsequently, laparoscopic diverting transverse colostomy was performed. The total operative time was $6 \mathrm{~h} 35 \mathrm{~min}$, and the estimated blood loss was 66 mL. No blood transfusion was needed.

The whole specimen was histologically examined with a 5-mm sliced block. A histological examination showed that the tumor cells had spread into the epidermis. No dermal invasion, stromal invasion, or lymphovascular invasion were observed. The tumor cells were cytokeratin (CK)7 positive and CK20 negative (Fig. 2). The diagnosis of noninvasive EMPD was confirmed. All surgical margins of both the perianal skin and the rectum mucosa were pathologically negative. The patient recovered without complications and underwent follow-up examinations every 6 months with local surveillance and enhanced CT.

At a follow-up examination at 2 years and 6 months after surgery, enhanced CT revealed enlargement of the lymph nodes in both the left inguinal and para-aortic areas (Fig. 3a). Local recurrence in the perianal region was not detected by a physical examination, $\mathrm{CT}$, or ${ }^{18} \mathrm{~F}-$ fluorodeoxyglucose-PET (Fig. 3b). Excision biopsy of the left inguinal lymph node was performed, and the recurrence of Paget's disease was histologically diagnosed. The patient subsequently underwent chemotherapy (FOLFOX plus cetuximab and FOLFIRI plus bevacizumab), without remarkable effect. One year later, multiple bone metastases manifested, and the patient died of the disease 53 months after the first surgery.

\section{Discussion}

EMPD is an uncommon malignancy of the skin, classified as an intraepithelial adenocarcinoma that most frequently occurs in regions with an abundance of apocrine glands. The most commonly affected are the vulva, scrotum, and perianal areas [6]. EMPD represents 6.5\% of all Paget's cases [7]. The perianal skin is a relatively common area for EMPD; however, the precise incidence is unknown [8]. EMPD is thought to be segregated into 2 groups: primary EMPD, which is confined to only the epidermis and dermis; and secondary EMPD, which involves genitourinary or rectal cancer. Thus, clinicians should search for underlying malignancy in patients with EMPD [9]. The etiology of primary EMPD has been debated but appears to be of apocrine origin, whereas secondary EMPD represents an extension of underlying visceral malignancy that is commonly urothelial, cervical, or anorectal.

Treatment of primary EMPD remains challenging and controversial mainly due to the rareness of the disease; however, excision with a proper margin has been considered to be the gold standard of treatment. Primary EMPD should be classified into noninvasive and invasive EMPD. In noninvasive EMPD, tumor cells exist within the epidermis without dermal or lymphovascular invasion, whereas invasive EMPD spreads to the dermal layer [5]. Noninvasive EMPD can be completely excised by wide resection, and the defect can be closed with a skin flap. The literature recommends a safe resection margin of $2 \mathrm{~cm}$. The prognosis of noninvasive EMPD is commonly favorable when complete resection is completed, in comparison to invasive primary EMPD or secondary EMPD [8]. 


\section{Case Reports in Gastroenterology}

Case Rep Gastroenterol 2020;14:402-408

DOI: $10.1159 / 000508859$

(C) 2020 The Author(s). Published by S. Karger AG, Basel www.karger.com/crg

Maeda et al.: Recurrence of Noninvasive Perianal Extramammary Paget's Disease in the Lymph Nodes without Local Recurrence after Complete Excision

Multiple studies have demonstrated a substantial risk of lymph node metastasis in patients with invasive EPMD, with a reported incidence ranging from 16.9 to $37 \%$ [1, 2]. In a multi-institute retrospective analysis of sentinel lymph node biopsy (SLNB) of 107 patients without clinical lymphadenopathy, Fujisawa et al. [1] reported that occult lymph node metastasis was detected by SLNB in 15\% of the cases; thus, SLNB should be considered for invasive EMPD. On the other hand, lymph node metastasis is reported to be absent in patients with noninvasive disease $[3-5,10]$ (Table 1 ). Thus, prophylactic or sentinel lymph node dissection is not recommended in noninvasive EMPD $[1,11,12]$.

The present case was diagnosed as primary EMPD, since internal malignancy was ruled out based on CT and colonoscopy. This disease was also classified as noninvasive EMPD, since presence of tumor cells was limited to the epidermis in the histological examination of the whole resected specimen with 5-mm slices. Despite the complete surgical margins, the patient developed inguinal and para-aortic lymph node recurrence without local recurrence. All reported recurrent cases of originally noninvasive perianal EMPD have been associated with local recurrence. Only a few cases of local lymph node metastasis have been reported in cases of scrotum EMPD [13]. To the best of our knowledge, no other recurrent cases have been reported among noninvasive EMPD of the vulva or perianal skin [3-6, 14].

In the present case, the noninvasive lesion of the perianal area was completely resected with a pathologically confirmed negative margin. However, inguinal and para-aortic lymph node metastasis occurred after 2.5 years without local recurrence. Local recurrence was not observed in the present case, even in the terminal stage of the disease. We hypothesize that lymph node micro-metastasis occurred prior to the resection of the primary lesion. There are 3 potential mechanisms explaining lymph node metastasis without local recurrence after complete resection. One possible mechanism of metastasis from noninvasive EMPD is thought to be the spontaneous regression of an invasive component. The spontaneous regression of EMPD has been described in the literature after surgical excision following preoperative biopsy $[13,15]$. In such cases, lymph node metastasis might have occurred during the time when an invasive component existed. Another possible theory may involve the nature of the skipping spread of EMPD. The discontinuous spread of Pagetoid cells in epidermis beyond the clinically apparent margin has been reported, especially in the cases with relatively large lesions [5]. Many authors recommend preoperative step biopsy with a wide surgical margin from the edge of the visible lesion [10]. The third possible theory is the potential presence of micro-dermal invasion. Though a histological examination of 5-mm slices of the whole resected specimen was performed in the present case, the potential presence of micro-invasion between sliced blocks cannot be completely denied. Fujisawa et al. [1] reported that in SLNB, lymph node metastasis was detected in 5\% of the micro-invasive EMPD cases. All these potential theories suggest that careful follow-up for recurrence should be recommended, even in completely resected noninvasive EMPD cases, especially for cases with a large lesion or long period of disease before treatment.

In conclusion, we reported an extremely rare case of noninvasive perianal EMPD that recurred in the inguinal and para-aortic lymph nodes without local recurrence after complete excision. Treatment of EMPD remains challenging and controversial due to the rarity of the disease. It is important to share the experience of cases globally. Clinicians need to consider the possibility of lymph node or distant metastasis, even in cases with completely resected noninvasive EMPD. 


\section{Case Reports in Gastroenterology}

\section{Statement of Ethics}

Informed consent was obtained from the patient for publication of the case report and relevant images.

\section{Conflict of Interest Statement}

The authors have no conflicts of interest to declare.

\section{Funding Sources}

This work received no funding.

\section{Author Contributions}

Y. Maeda and T. Shinohara are the primary investigators in this case report and contributed to conceptualization, data collection, and drafting of the manuscript. All authors read and approved the manuscript for publication.

\section{References}

1 Fujisawa Y, Yoshino K, Kiyohara Y, Kadono T, Murata Y, Uhara H, et al. The role of sentinel lymph node biopsy in the management of invasive extramammary Paget's disease: Multi-center, retrospective study of 151 patients. J Dermatol Sci. 2015 Jul;79(1):38-42.

2 Ohara K, Fujisawa Y, Yoshino K, Kiyohara Y, Kadono T, Murata Y, et al. A proposal for a TNM staging system for extramammary Paget disease: retrospective analysis of 301 patients with invasive primary tumors. J Dermatol Sci. 2016 Sep;83(3):234-9.

3 Niikura H, Yoshida H, Ito K, Takano T, Watanabe H, Aiba S, et al. Paget's disease of the vulva: clinicopathologic study of type 1 cases treated at a single institution. Int J Gynecol Cancer. 2006 MayJun;16(3):1212-5.

4 Nomura H, Matoda M, Okamoto S, Kondo E, Omatsu K, Kato K, et al. Clinicopathologic features and treatment outcomes of primary extramammary Paget disease of the vulva. J Low Genit Tract Dis. 2015 Apr;19(2):1458.

5 Perez DR, Trakarnsanga A, Shia J, Nash GM, Temple LK, Paty PB, et al. Management and outcome of perianal Paget's disease: a 6-decade institutional experience. Dis Colon Rectum. 2014 Jun;57(6):747-51.

6 Wollina U, Goldman A, Bieneck A, Abdel-Naser MB, Petersen S. Surgical Treatment for Extramammary Paget's Disease. Curr Treat Options Oncol. 2018 May;19(6):27.

7 Kyriazanos ID, Stamos NP, Miliadis L, Noussis G, Stoidis CN. Extra-mammary Paget's disease of the perianal region: a review of the literature emphasizing the operative management technique. Surg Oncol. 2011 Jun;20(2):e61-71.

8 McDaniel B, Brown F, Crane JS. Extramammary Paget Disease. StatPearls [Internet]. Treasure Island (FL): StatPearls Publishing; 2019.

9 Harris DW, Kist DA, Bloom K, Zachary CB. Rapid staining with carcinoembryonic antigen aids limited excision of extramammary Paget's disease treated by Mohs surgery. J Dermatol Surg Oncol. 1994 Apr;20(4):260-4.

10 Asel M, LeBoeuf NR. Extramammary Paget's Disease. Hematol Oncol Clin North Am. 2019 Feb;33(1):73-85. 


\section{Case Reports in Gastroenterology}

\begin{tabular}{l|l}
\hline Case Rep Gastroenterol 2020;14:402-408 \\
\hline DOI: 10.1159/000508859 & $\begin{array}{l}\text { @ 2020 The Author(s). Published by S. Karger AG, Basel } \\
\text { www.karger.com/crg }\end{array}$ \\
\hline
\end{tabular}

Maeda et al.: Recurrence of Noninvasive Perianal Extramammary Paget's Disease in the Lymph Nodes without Local Recurrence after Complete Excision

11 Zollo JD, Zeitouni NC. The Roswell Park Cancer Institute experience with extramammary Paget's disease. Br J Dermatol. 2000 Jan;142(1):59-65.

12 Mehta NJ, Torno R, Sorra T. Extramammary Paget's disease. South Med J. 2000 Jul;93(7):713-5.

13 Hioki M, Ohshita A, Yoshida S, Kanehisa F, Katoh N, Asai J. Pelvic lymph node metastasis in extramammary Paget disease of the scrotum without inguinal lymph node metastasis. Australas J Dermatol. 2019 May;60(2):151-3.

14 Fan L, Zhu J, Tao X, Xu C. Intraepithelial Extramammary Paget's Disease of the Vulva: The Clinicopathological Characteristics, Management, and Outcome in a Study of 18 Female Patients. Dermatol Surg. 2016 Oct;42(10):1142-6.

15 Archer CB, Louback JB, MacDonald DM. Spontaneous regression of perianal extramammary Paget's disease after partial surgical excision. Arch Dermatol. 1987 Mar;123(3):379-82.
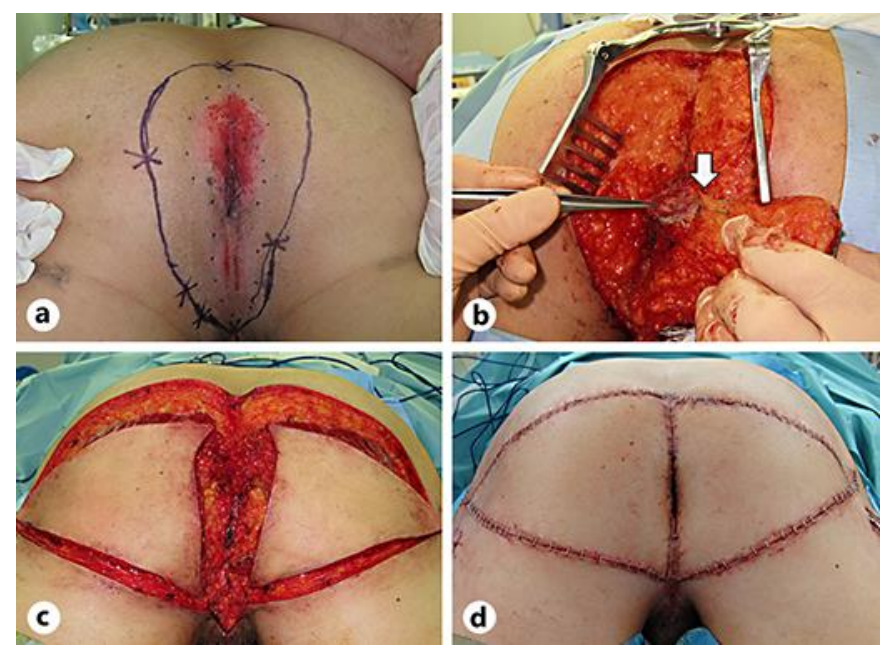

Fig. 1. a Erythematous skin rash of $7 \times 5 \mathrm{~cm}$ in the perianal region, with erosive and eczematous change. The patient was placed in a jack-knife position. Circumferential excision margin of at least $2.5 \mathrm{~cm}$ was designed. b Subcutaneous fat tissue was resected to a thickness of approximately $10 \mathrm{~mm}$. Resection was performed into the inter-sphincter space between the internal and external sphincter muscle of the lower rectum. The lower rectum was resected continuously with the perianal skin over a length of $3 \mathrm{~cm}$ from the dentate line. The white arrow shows the rectum edge. $\mathbf{c}$ The defect was closed by using a VY-advancement flap. $\mathbf{d}$ Anastomosis of the flap and residual rectum was performed. 


\section{Case Reports in Gastroenterology}


Fig. 2. a A histological examination showed tumor cells in the epidermis $(\times 200)$. The tumor cells were positive for CK7 (b) and negative for CK20 (c) ( $\times 40)$.
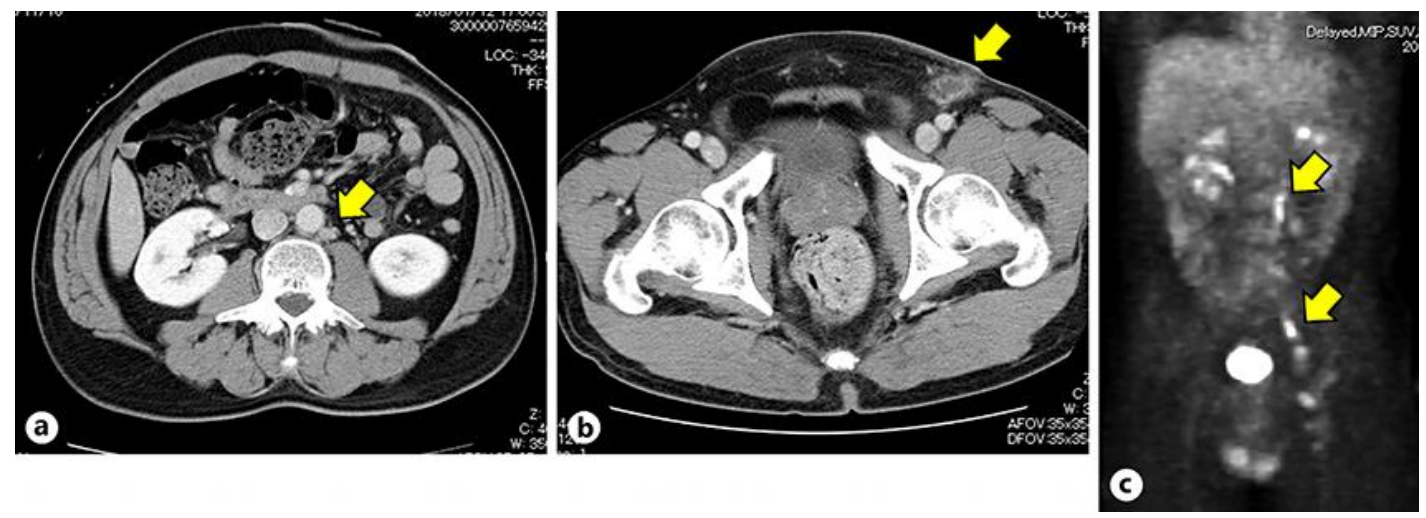

Fig. 3. a, b Enhanced CT performed after 2.5 years showed lymphadenopathy spreading from the left inguinal and para-aortic area (yellow arrows). c Positron emission tomography showed the increased uptake of 18F-fluorodeoxyglucose by the left inguinal and para-aortic lymph nodes (yellow arrows).

Table 1. Reported incidence of metastasis and recurrence from noninvasive EMPD

\begin{tabular}{|c|c|c|c|c|c|c|c|c|}
\hline Ref. & Year & $\begin{array}{l}\text { First } \\
\text { author }\end{array}$ & Site & $\begin{array}{l}\text { Noninvasive } \\
\text { cases }\end{array}$ & $\begin{array}{l}\text { Lymph node } \\
\text { metastasis }\end{array}$ & $\begin{array}{l}\text { Distant } \\
\text { metastasis }\end{array}$ & $\begin{array}{l}\text { Local } \\
\text { recurrence }\end{array}$ & $\begin{array}{l}\text { Lymph node } \\
\text { or distant } \\
\text { recurrence }\end{array}$ \\
\hline 3 & 2006 & Niikura & vulva & 18 & 0 & 0 & 0 & 0 \\
\hline 4 & 2015 & Nomura & vulva & 11 & 0 & 0 & 1 & 0 \\
\hline 5 & 2014 & Perez & perianal & 24 & 0 & 0 & 12 & 0 \\
\hline
\end{tabular}

